\title{
Redescription of Dracunculus globocephalus Mackin, 1927 (Nematoda: Dracunculidae), a parasite of the snapping turtle, Chelydra serpentina
}

\author{
František Moravec $^{1}$ and M.D. Little ${ }^{2}$ \\ ${ }^{1}$ Institute of Parasitology, Academy of Sciences of the Czech Republic, Branišovská 31, 37005 České Budějovice, Czech \\ Republic; \\ ${ }^{2}$ Department of Tropical Medicine, Tulane University Medical Center, 1440 Canal Street, New Orleans, LA 70112, USA
}

Key words: Nematoda, Dracunculus, parasite, morphology, turtle, Chelydra, Louisiana, USA

\begin{abstract}
Dracunculus globocephalus Mackin, 1927 (Nematoda: Dracunculoidea) is redescribed from specimens collected from the mesentery of the snapping turtle, Chelydra serpentina (L.), in Louisiana, USA. The use of scanning electron microscopy, applied for the first time in this species, made it possible to study details in the structure of the cephalic end and the arrangement of male caudal papillae that are difficult to observe under the light microscope. This species markedly differs from all other species of Dracunculus in having the spicules greatly unequal in size and shape, in the absence of a gubernaculum, and in the disposition of male caudal papillae. The validity of $D$. globocephalus is confirmed, but the above mentioned morphological differences are not sufficient for listing it in a separate genus. This is the first record of D. globocephalus in Louisiana.
\end{abstract}

Morphology of most species of the family Dracunculidae is inadequately known and this is reflected in different opinions on the classification system and the delimitation of genera in this nematode group (Muller 1971). To date, 13 nominal species of Dracunculus Reichard, 1759 have been established, all histozoic parasites of mammals (including man) and reptiles. Because of the morphological similarity of all Dracunculus species and the recorded intraspecific variability of some morphological features, the validity of some described species was questioned (e.g., Mirza 1957, Mirza and Roberts 1957); Mirza (1957) even assumed the existence of only two species of Dracunculus: one which parasitizes the mammals and the other which parasitizes the reptiles. His opinion was followed in the monograph by Ivashkin et al. (1971), who considered only D. medinensis (Linnaeus, 1758) and D. oesophageus (Polonio, 1859) to be valid and synonymized all the remaining congeneric species with them.

On the contrary, Yamaguti (1961) established independent genera Chelonidracunculus [type species $C$. globocephalus (Mackin, 1927)] and Ophiodracunculus [type species $O$. oesophageus (Polonio, 1859)] for the species previously reported in Dracunculus and parasitic in turtles and snakes, respectively. However, these two genera have not been accepted by subsequent authors (e.g., Crites 1963, Ivashkin et al. 1971, Muller 1971, Chabaud 1975, Baker 1987). Apparently, the existing taxonomic problems in Dracunculus spp. can be solved only by detailed comparative studies of individual species, including morphological, biological and molecular studies (Moravec 2004).
Dracunculus globocephalus, as the only species of the genus from turtles, was first described by Mackin (1927) from the body cavity and mesenteries of the snapping turtle, Chelydra serpentina (Linnaeus, 1758) from Oklahoma and Illinois, USA. The author distinguished it from other congeners by the markedly unequal spicules and the number and arrangement of papillae in the male. However, Mirza (1957) and Mirza and Roberts (1957) compared the type specimens of $D$. globocephalus with those newly collected from the North American snake Nerodia sipedon (Linnaeus, 1758) and considered to be D. ophidensis Brackett, 1938, and stated that these were identical. Their opinion is not shared by Crites (1963). Gatschet and Schmidt (1974) redescribed this parasite from specimens collected from C. serpentina in Colorado, USA, but their brief redescription, based solely on light microscopy, is inaccurate and misleading in some respects.

During a short visit of the first author of this paper (F.M.) to Louisiana, USA in 1987, a single male of the snapping turtle, $C$. serpentina, was examined and, in addition to some other helminth parasites, 10 specimens of D. globocephalus were found in its mesentery near the rectum. This material made it possible to study in detail the morphology of this nematode, using both light and scanning electron microscopy, and to redescribe the species.

\section{MATERIALS AND METHODS}

A single male specimen of the snapping turtle, Chelydra serpentina (L.) (Chelydridae: Testudines), was captured in swamps near the town of La Place (about $40 \mathrm{~km}$ west of New 
Orleans), Louisiana, USA on 20 April 1987. After its transportation to the laboratory of the Tulane University Medical Center in New Orleans, the turtle was killed and examined for the presence of helminth parasites. The nematodes were fixed in hot $4 \%$ formaldehyde solution in physiological saline and cleared with glycerine for examination. Drawings were made with the aid of a Zeiss microscope drawing attachment. After examination, the specimens were briefly placed in $4 \%$ formaldehyde solution and then transferred to $70 \%$ ethanol, in which they were stored. For scanning electron microscopy (SEM), anterior and posterior ends of 1 male and 2 females were postfixed in $1 \%$ osmium tetroxide, dehydrated through a graded ethanol series, critical point dried, and sputter-coated with gold. They were examined with a JEOL JSM-6300 scanning electron microscope at an accelerating voltage of $15 \mathrm{kV}$. All measurements are given in millimetres unless otherwise stated. The specimens have been deposited in the Helminthological Collection of the Institute of Parasitology, Academy of Sciences of the Czech Republic, in České Budějovice (cat. no. N-255).

\section{DESCRIPTION}

Family D r a c u n c u 1 i d a e Stiles, 1907

\section{Dracunculus globocephalus Mackin, 1927}

Figs. 1-3

General. Body filiform, white; anterior end of body usually with slight constriction just anterior to level of nerve ring, giving appearance of neck; cephalic end narrowed, rounded, somewhat depressed dorsoventrally, with yellow peribuccal ring; posterior region attenuated; tail conical, with sharply pointed tip. Cuticle finely transversely striated. Oral aperture small, circular, mouth with three oesophageal sectors at bottom. Eight cephalic papillae present, arranged in two circles: inner circle formed by pair of large dorsal and ventral anteriorly-projecting dome-shaped papillae with double nerve endings and pair of small lateral simple papillae; outer circle formed by four submedian papillae with double nerve endings; lateral amphids conspicuous, situated between dorsolateral and ventrolateral papillae of outer circle (Figs. 2 A-D, 3 A-C). Small deirids situated at short distance posterior to level of nerve ring (Fig. $1 \mathrm{~B}$ ). Excretory pore at about level of deirids. Oesophagus very long, consisting of short, narrow anterior muscular portion and very long glandular portion; glandular oesophagus encircled by nerve ring at short distance anterior to deirids and excretory pore, dividing it into anterior, inflated portion and very long posterior portion opening into intestine through valve; glandular oesophagus markedly narrowed at level of nerve ring (Figs. 1 A,B, 2 A). Oesophagus opens into intestine through valve 0.068 long. Intestine light-coloured. Tail conical, with sharply pointed tip.

Male (3 specimens): Length of body 18.9-21.7, maximum width $0.231-0.258$; width of anterior end of body anterior to constriction $0.218-0.245$. Height of dorsoventral cephalic papillae $0.015-0.018$. Oesophagus $10.468-12.008$ long, 48-62\% of body length. Muscular oesophagus $0.225-0.285$ long and $0.039-0.051$ wide; entire glandular oesophagus 10.243-11.723 long, length of its anterior part $0.394-0.435$, width $0.150-0.190$, of its posterior part 9.806-11.329, maximum width 0.136 0.177 , width at level of constriction 0.042-0.045. Nerve ring, deirids and excretory pore $0.734-0.762,0.844$ 0.898 and 0.911-1.020, respectively, from anterior extremity. Posterior end of body spirally coiled. Ventral precloacal surface without cuticular ornamentations. Caudal papillae: one preanal median papilla with two nerve endings situated just anterior to cloacal aperture; two groups, each consisting of six weakly developed, close to each other subventral adanal papillae and two pairs of subventral postanal papillae present; anterior postanal papillae small, situated just posterior to adanal papillae, posterior postanal papillae larger, situated at about middle of tail (Figs. 1 F,G, 3 D-F). Spicules brown, markedly unequal in length, with sharply pointed tips: right spicule needle-like, non-alate, $0.963-$ 1.062 long, its proximal end, middle part and distal end $0.021,0.006$ and 0.003 , respectively, wide; left spicule $0.186-0.213$ long, with ventral membranous ala at its distal half, its proximal end, middle part and distal end $0.021-0.024,0.015-0.018$ and 0.003 , respectively, wide (Fig. $1 \mathrm{C}-\mathrm{F}$ ). Length ratio of spicules $1: 4.99-5.18$. Gubernaculum absent. Tail conical, 0.367-0.381 long.

Female (5 gravid specimens containing larvae): Length of body 91.6-121.8, maximum width $0.721-$ 0.830 (two subgravid specimens containing eggs 46.512-68.612 long, maximum width 0.490-0.571); width of anterior end of body anterior to constriction 0.585-0.707. Height of dorsoventral cephalic papillae 0.015-0.027. Entire oesophagus 31.498-32.232 long, forming $26-34 \%$ of body length. Muscular oesophagus $0.408-0.544$ long and 0.095-0.109 wide; entire glandular oesophagus 31.090-31.824 long, length of its anterior part $1.047-1.156$, width $0.422-0.544$, of its posterior part 29.934-30.736, maximum width 0.367-0.476, width at level of constriction $0.082-0.136$. Nerve ring, deirids and excretory pore $1.550-2.162,1.972-2.244$ and 1.292-2.162, respectively, from anterior extremity. Rectum short hyaline tube. Tail $0.762-0.870$ long, with small cuticular spike at tip. Genital system amphidelphic. Ovaries short, anterior ovary situated in region of glandular oesophagus, posterior ovary in region of rectum. Vulva inconspicuous, slightly postequatorial, situated 48.362-65.824 from anterior extremity (at 53$55 \%$ of body length); short, narrow muscular vagina present (Fig. 2 F). Uterus extending through major part of body, being filled with numerous first-stage larvae. Larvae $(\mathrm{n}=10)$ 0.666-0.721 long, maximum width 0.021 , with slender, sharply pointed tail $0.258-0.288$ long (39-40\% of body length); oesophagus $0.090-0.129$ long (13-19\%). 

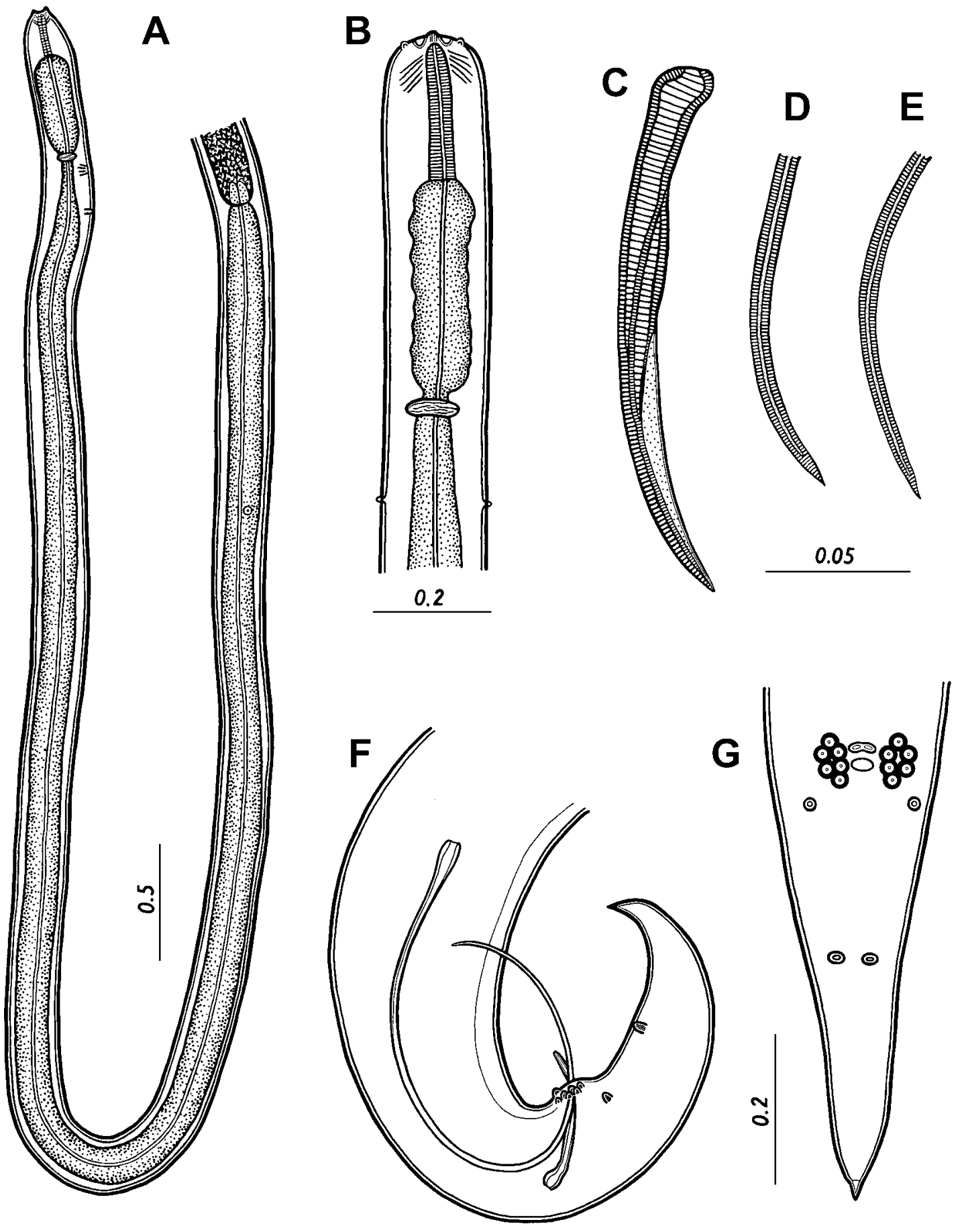

Fig. 1. Dracunculus globocephalus Mackin, 1927, male. A - oesophageal part of body, lateral view; B - anterior end of body, dorsoventral view; $\mathbf{C}$ - small (left) spicule; $\mathbf{D}, \mathbf{E}$ - distal end of large (right) spicule; $\mathbf{F}$ - posterior end of male, lateral view; $\mathbf{G}-$ tail of male, ventral view. Scale bars in $\mathrm{mm}$. 

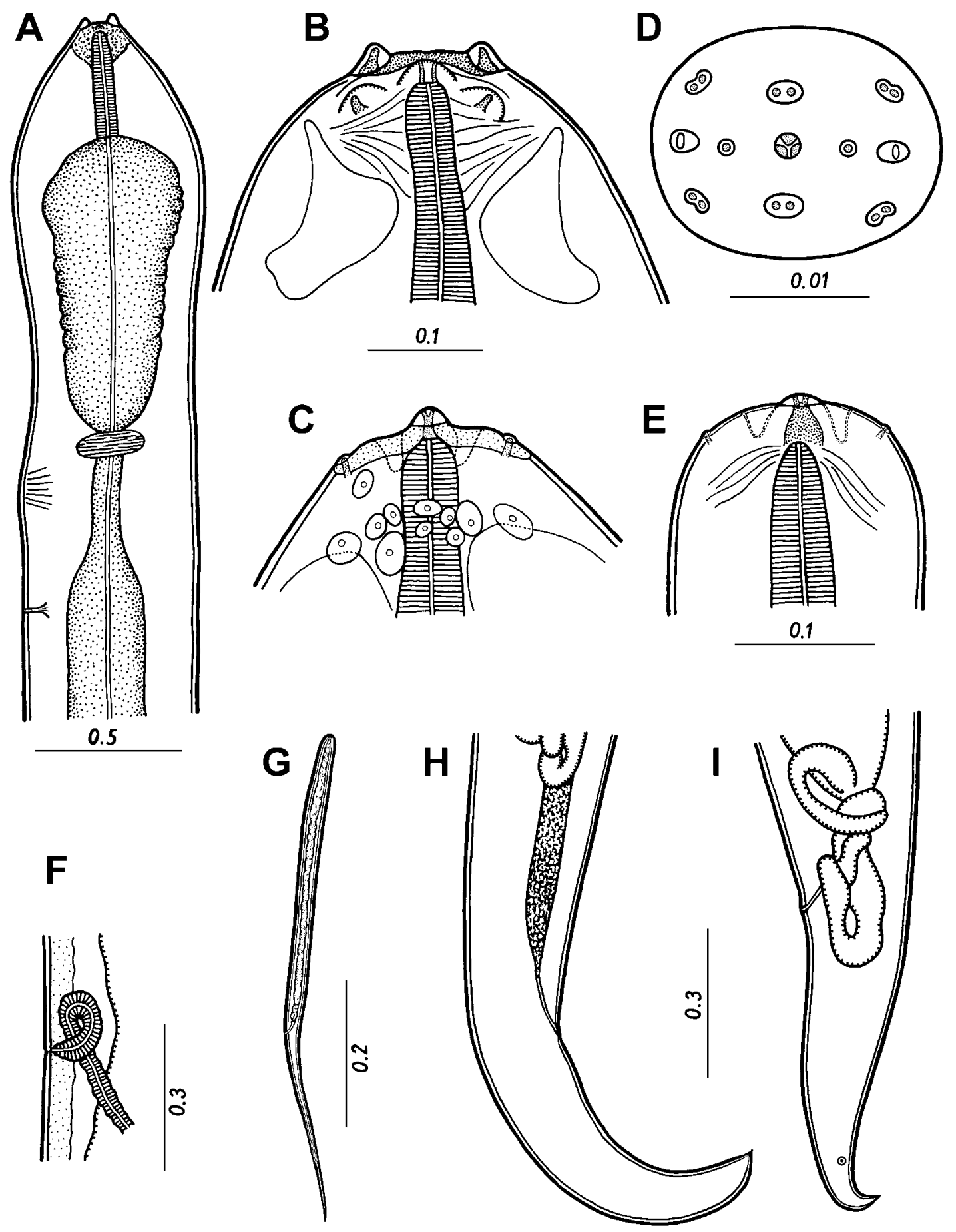

Fig. 2. Dracunculus globocephalus Mackin, 1927. A - anterior end of body of gravid female, lateral view; B, C - cephalic end of gravid female, lateral and dorsoventral views; D - same, apical view (reconstructed from scanning electron micrographs); E cephalic end of male, dorsoventral view; $\mathbf{F}$ - region of vulva, lateral view; $\mathbf{G}$ - larva from uterus; $\mathbf{H}, \mathbf{I}$ - caudal end of younger and older gravid females, lateral views. Scale bars in $\mathrm{mm}$. 

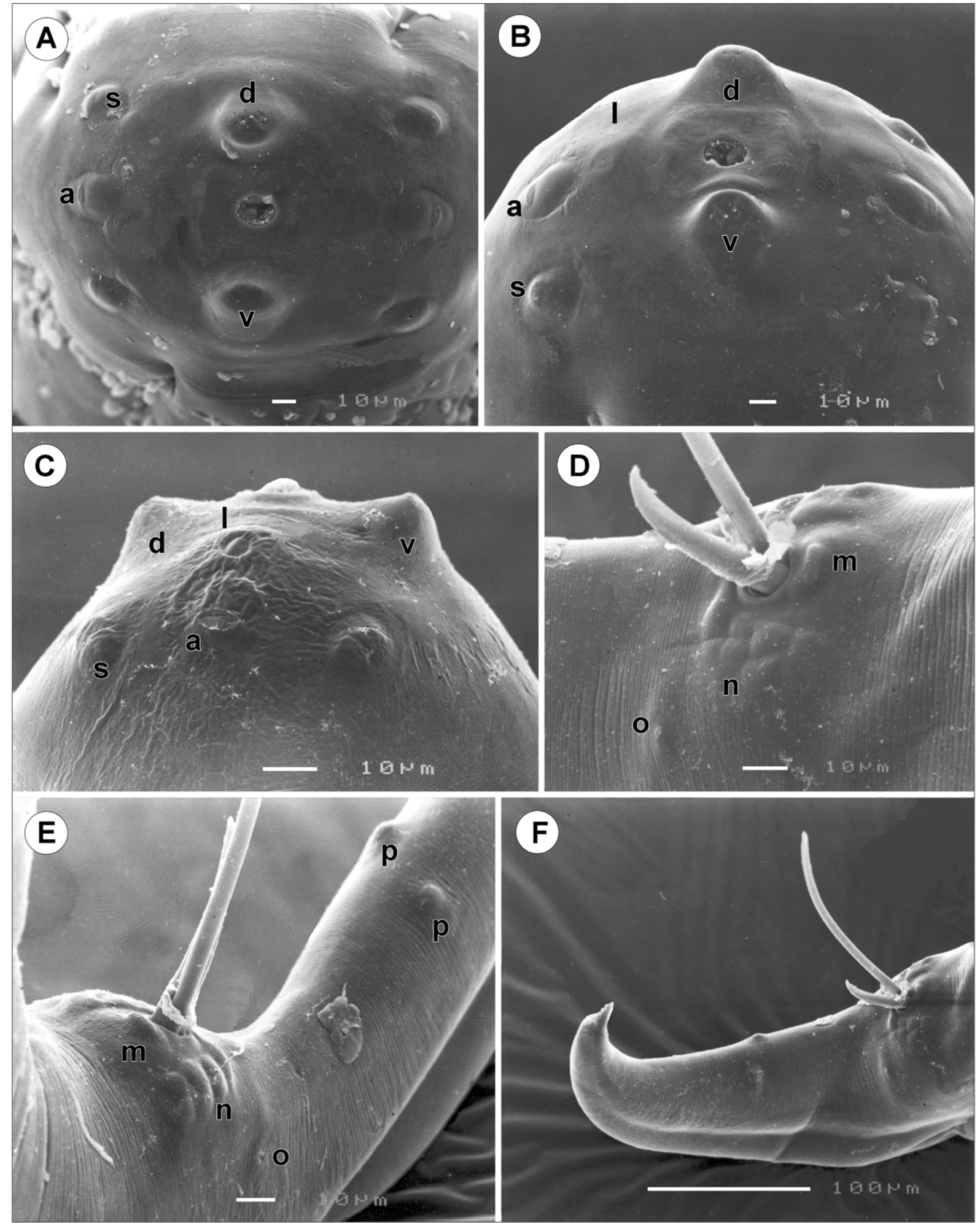

Fig. 3. Dracunculus globocephalus Mackin, 1927, scanning electron micrographs. A, B - cephalic end of gravid female, apical and dorsoventral views; C - cephalic end of gravid female (another specimen), lateral view; D, E - arrangement of caudal papillae near cloaca in male, subventral and sublateral views; $\mathbf{F}$ - tail of male, subventral view. a - amphid; $\mathrm{d}$ - dorsal cephalic papilla; 1 - lateral cephalic papilla; $\mathrm{m}$ - median preanal papilla; $\mathrm{n}$ - group of adanal papillae; $\mathrm{o}$ - papillae of first postanal pair; $\mathrm{p}$ - papilla of second postanal pair; $\mathrm{s}$ - submedian cephalic papilla; $\mathrm{v}$ - ventral cephalic papilla. 


\section{DISCUSSION}

Although certain morphological variations of the cephalic structures have been reported in Dracunculus spp. (see, e.g., Ivashkin et al. 1971), the existing data were based only on light microscopy examinations; to date, the cephalic end has not been studied by SEM in any species of Dracunculus. However, some details of the cephalic structure in dracunculoids are not easily visible under the light microscope and the only reliable method to study them is the use of SEM (Moravec 2004).

The cephalic end of $D$. globocephalus was relatively well described by Mackin (1927), but he did not distinguish between small lateral papillae and larger amphids, writing that "the next in size is the lateral pair, each one of which is double, having two nerve endings to each of the cone-shaped papillae". Hsü (1933), while describing a new Dracunculus species, D. houdemeri, from snakes in China, re-examined the specimens of $D$. globocephalus provided by Mackin; he found in it, like in D. houdemeri, two lateral amphids, and one dorsal, one ventral, two lateral and four submedian papillae, of which the dorsal, ventral and submedian papillae all had double nerve endings. Later Gatschet and Schmidt (1974) gave a schematic drawing of the apical view of the cephalic end of D. globocephalus, reporting submedian papillae to be simple, whereas dorsal, ventral and lateral papillae each to have two nerve endings.

The present study confirms the observations by Hsü (1933) that, in this species, the dorsal, ventral and submedian papillae each have two nerve endings, whereas the lateral papillae are simple (Figs. 2 D, 3 A-C). However, in contrast to the latter author, the dorsal and ventral papillae were found to be conspicuously large, anteriorly protruding. Instead of single dorsal and ventral papillae, some Dracunculus spp. are reported to possess two dorsal and two ventral papillae, which may be partly fused together in some species or specimens. For example, D. ophidensis Brackett, 1938 from North American snakes was described to have two dorsal and two ventral papillae (Brackett 1938), but this should be verified by SEM. Differences in the structure of the cephalic end might be useful for the separation of some Dracunculus spp., especially in cases when males are not available.

The presence of conspicuously large single dorsal and ventral papillae is also typical of nematodes of another dracunculoid genus, Daniconema Moravec et Køie, 1987, including parasites of eels, whereas small lateral papillae are found in members of many dracunculoid genera (e.g., Philometra Costa, 1845, Granulinema Moravec et Little, 1988, Dentiphilometra Moravec et Wang, 2002, Histodytes Aragort, Álvarez, Iglesias, Leiro et Sanmartín, 2002) (Moravec 2004).

All specimens of the present material had a slight "neck" constriction just anterior to the level of the nerve ring, already mentioned by Mackin (1927). Although
Gatschet and Schmidt (1974) write that there are no deirids in D. globocephalus, the present material confirms the observation by Mackin (1927) that minute deirids are present (Fig. 2 B). Deirids are very small and difficult to find in Dracunculus spp. and they have rarely been reported in these nematodes (e.g., Brackett 1938, Desportes 1938, Chabaud 1960, Vaucher and Bain 1973).

One of the main features by which Mackin (1927) distinguished D. globocephalus from other Dracunculus spp. was the presence of the markedly unequal spicules (0.8 $\mathrm{mm}$ and $0.2 \mathrm{~mm}$ long). However, this was questioned by Mirza (1957) and Mirza and Roberts (1957); because the latter authors found some specimens of $D$. ophidensis from the North American snake Nerodia sipedon (L.) to be somewhat unequal $(0.214 \mathrm{~mm}$ and $0.187 \mathrm{~mm})$, they state that in their opinion the nematodes described by Mackin (1927) from turtles and those described by Brackett (1938) from the snake are identical; Mirza (1957) examined type specimens of D. globocephalus, compared them with the specimens from $N$. sipedon, and stated that he found them identical. But Gatschet and Schmidt (1973) did not agree and described spicules of newly collected $D$. globocephalus as greatly unequal in size and shape. Unfortunately, their measurements of spicules are evidently confused. The measurements of spicules in males of the present material are similar to those reported by Mackin (1927) and their length ratios are also similar (1:4.99-5.18 and $1: 4)$; on the contrary, the spicule ratio of the specimens from $N$. sipedon given by Mirza and Robers (1957) is very different (at most $1: 1.14$ ) and it is clear that they belonged to another species, D. ophidensis. Dracunculus globocephalus differs from $D$. ophidensis also in the absence of a gubernaculum, which is confirmed in this study.

Mackin (1927) reported only one unpaired median preanal papilla and one pair of subventral postanal papillae situated slightly anterior to the middle of the tail in the male of D. globocephalus. According to Gatschet and Schmidt (1973), males of this species have the following caudal papillae: one median papilla and two pairs of small subventral preanal papillae; and two pairs of small subventral postanal papillae followed by one pair of large subventral postanal papillae in about the middle of the tail. However, it is necessary to state that most caudal papillae in Dracunculus spp. are difficult to observe under the light microscope, but the use of SEM has not yet been applied to study them in any species of Dracunculus. The present study shows that the actual number and distribution of caudal papillae (Figs. 1 F,G, 3 D-F) are very different from those reported by previous authors for D. globocephalus, which distinctly differentiates this species from all other congeners.

Most species of Dracunculus, both those parasitizing mammals and reptiles, are considered to be morpho- 
logically very similar to each other and Ivashkin et al. (1971) even recognized as valid only D. medinensis from mammals and $D$. oesophageus from reptiles. Regarding species parasitic in reptiles, Ivashkin et al. (1971) synonymized D. dahomensis (Neumann, 1895), D. globocephalus Mackin, 1927, D. houdemeri Hsü, 1933, D. ophidensis Brackett, 1938, D. doi Chabaud, 1960 and D. alii Deshmukh, 1969 with D. oesophageus, mentioning that $D$. coluberensis Deshmukh, 1969 is apparently a representative of the order Filariata; an additional species, D. riccii Deshmukh, 1970, has been described since. However, most of these species are dealt with as valid by subsequent authors (e.g., Muller 1971, Vaucher and Bain 1973, Baker 1987). Of them, D. globocephalus is the only species parasitic in turtles, whereas all the remaining species occur in snakes.

The present study clearly shows that D. globocephalus differs markedly from all other species in the genus, both those parasitic in snakes and mammals, mainly in possessing the spicules greatly unequal in size and shape (vs. equal or subequal), in the absence of a gubernaculum, and in the disposition of male caudal papillae (subventral groups of papillae near cloaca are distinctly preanal in other species), confirming thus its validity. However, we consider these differences only as interspecific, insufficient for creating an independent genus (see Yamaguti 1961) and, consequently, this species should be retained in the genus Dracunculus.

Dracunculus globocephalus seems to be a specific parasite of the snapping turtle, Chelydra serpentina, in North America, but it has not been frequently recorded. So far it has been reported only from the USA from Colorado, Illinois, Louisiana, Ohio and Oklahoma (Mackin 1927, Crites 1963, Gatschet and Schmidt 1974, present study).

Acknowledgements. The authors wish to thank Barry G. Campbell, a former student at the Tulane University in New Orleans, for his help with the dissection of $C$. serpentina, to the staff of the Laboratory of Electron Microscopy, Institute of Parasitology, ASCR, in České Budějovice for their technical assistance, and to Irena Husáková, a technician of the same Institute, for her help with illustrations. This study was supported by the grant 524/03/0061 from the Grant Agency of the Czech Republic and the research project of the Institute of Parasitology, ASCR (no. Z6 022 909).

\section{REFERENCES}

BAKER M.R. 1987: Synopsis of the Nematoda Parasitic in Amphibians and Reptiles. Occasional Papers in Biology, Memorial University of Newfoundland, No. 11, $325 \mathrm{pp}$.

BRACKETT S. 1938: Description and life history of the nematode Dracunculus ophidensis n. sp., with a redescription of the genus. J. Parasitol. 24: 353-361.

CHABAUD A.G. 1960: Deux nematodes parasites de serpents malgaches. Mém. Inst. Sci. Madagascar, Sér. A, 14: 95103.

CHABAUD A.G. 1975: Keys to genera of the order Spirurida, Part 1. Camallanoidea, Dracunculoidea, Gnathostomatoidea, Physalopteroidea, Rictularioidea and Thelazioidea. $\mathrm{CIH}$ keys to the nematode parasites of vertebrates 3 . Commonwealth Agricultural Bureaux, Farnham Royal, Bucks, UK, 27 pp.

CRITES J.L. 1963: Dracontiasis in Ohio carnivores and reptiles with a discussion of the dracunculid taxonomic problem (Nematoda: Dracunculidae). Ohio J. Sci. 63: 1-6.

DESPORTES C. 1938: Filaria oesophagea Polonio 1859, parasite de la couleuvre d'Italie, est un Dracunculus très voisin de la filaire de Médine. Ann. Parasitol. 16: 305 326.

GATSCHET T.P., SCHMIDT G.D. 1974: A redescription of Dracunculus globocephalus Mackin, 1927 (Nematoda: Dracunculidae), a parasite of turtles. Helminthologia 15: 835-838.
HSÜ H.F. 1933: On Dracunculus houdemeri n. sp., Dracunculus globocephalus and Dracunculus medinensis. Z. Parasitenkd. 6: 101-118.

IVASHKIN V.M., SOBOLEV A.A., KHROMOVA L.A. 1971: [Camallanata of Animals and Man and the Diseases Caused by Them. Osnovy nematodologii 22.] Nauka, Moscow, 388 pp. (In Russian.)

MACKIN J.G. 1927: Dracunculus globocephalus nov. sp. from Chelydra serpentina. J. Parasitol. 14: 91-94.

MIRZA M.B. 1957: On Dracunculus Reichard, 1759, and its species. Z. Parasitenkd. 18: 44-47.

MIRZA M.B., ROBERTS L.S. 1957: A redescription of Dracunculus from a snake, Natrix sipedon Linn. Z. Parasitenkd. 18: 40-43.

MORAVEC F. 2004: Some aspects of the taxonomy and biology of dracunculoid nematodes parasitic in fishes: a review. Folia Parasitol. 51: 1-13.

MULLER R. 1971: Dracunculus and dracunculiasis. Adv. Parasitol. 9: 73-151.

VAUCHER C., BAIN O. 1973: Développement larvaire de Dracunculus doi (Nematoda), parasite d'un Serpent malgache, et description de la femelle. Ann. Parasitol. 48: 91-104.

YAMAGUTI S. 1961: The Nematodes of Vertebrates. Systema Helminthum III, Pts. 1, 2. Interscience Publishers, New York and London, 1261 pp. 